\title{
A FEITICEIRA DE MICHELET E O IDEAL ROMÂNTICO DE HEROÍSMO
}

Marcelo Mangini Dias

RESUMO: A proposta para o presente artigo é, a partir de uma leitura da obra A Feiticeira, de Jules Michelet, verificar em que medida sua personagem-tema pode ser considerada uma espécie de paradigma do que chamaremos aqui de "herói micheletiano". Jules Michelet, um dos mais importantes representantes da historiografia francesa oitocentista tem sua narrativa marcada pela presença de heróis trágicos que se nos apresentam como modelos românticos de heroísmo. Não obstante, nossa hipótese é a de que o modelo, para Michelet, serve a um propósito maior, o de colocar como protagonista aquele que será, ao longo de toda a sua vasta obra, seu grande tema: o povo.

Palavras-Chave: Historiografia francesa, Michelet, Revolução Francesa, Pensamento Político

Jules Michelet, historiador francês nascido em 1798, era um genuíno filho da Revolução. Em mais de um escrito ele afirmou ser sua visão da história um longo combate da liberdade contra a fatalidade. Autor de um volume assombroso de obras, o caráter monumental de seu trabalho se expressa também no tom épico de sua narrativa, na escolha de temas universais - e por vezes peculiares, como "O Amor", "A Mulher" e "O Povo" - e na sua abordagem romântica da história.

Trinta e cinco anos depois de sua primeira publicação - a tradução para o francês da obra do filósofo italiano Gianbattista Vico, uma de suas maiores influências - Michelet lança o livro $A$ Feiticeira.

\section{A Feiticeira}

No encerramento do livro, em um capítulo intitulado "Notas e Esclarecimentos", Michelet nos alerta para os riscos de um recurso que marca os primeiros capítulos da obra: a aproximação de sua narrativa com a estrutura de um romance. Ainda que possa ser questionada tal "metodologia", ele alerta que "tudo é histórico e fundado" ${ }^{33}$ (MICHELET, 1862, p. 401).

A história da feiticeira se confunde com a história da mulher na Idade Média, como também se confunde com a história do diabo no imaginário cristão medieval. Ao narrar a epopéia medieval da feiticeira, Michelet cria uma personagem que atravessa séculos e envelhece com a própria civilização européia do medievo. Sua longeva feiticeira é contraposta à estrutura social e à institucionalização do cristianismo. Enquanto as estruturas de poder cristão e feudal são monstruosidades únicas na história do mundo (MICHELET, 1862, p. 401), a feiticeira é um fio de luz que sobrevive às trevas medievais. 
Na medida em que a Igreja cristã negligencia a matéria e o corpo, o "único médico do povo, durante mil anos, foi a feiticeira"64 (MICHELET, 1862, p. x). A mesma Igreja que se tornará seu carrasco é responsável pelo seu nascimento. Afinal, é na desesperança, na coerção social e religiosa violenta, na miséria sistemática do mundo feudal justificada pela ideologia do cristianismo medieval que a mulher assume, pouco a pouco, o papel da verdadeira feiticeira. Se parte da sociedade européia medieval busca asilo nos braços de Satã, afirmará Michelet, com boa dose de energia, é porque o bom Deus cristão não Ihe oferecia o consolo esperado.

Antes de qualquer coisa Michelet acusa a Igreja de rejeitar a natureza. Ora, o camponês europeu é estreitamente ligado a essa natureza. Na medida em que ela é imputada como campo de ação de Satã, naturalmente o homem simples da Idade Média é empurrado em direção contrária aos mistérios de uma Igreja cada vez mais distante e hierarquizada.

Para se impor ao politeísmo greco-romano e ao paganismo bárbaro, o cristianismo se esforçou por destruir sistematicamente todos os símbolos desse passado a ser negado. O resultado, para Michelet, é que "um vazio enorme se fizera no mundo"65 (MICHELET, 1862, p. 29). Criar novas formas de interpretar o mundo, de agir ou pensar, representaria, nesse sistema, um constante risco de retomada de valores que deveriam manter-se sepultos. O livre pensar deveria ser extinto, " $a$ via lógica abandonada" (MICHELET, 1862, p. 35). O novo valor é, então, a imitação. As virtuosas histórias de vida dos santos, para Michelet tolas fantasias criadas pelas férteis mentes camponesas impedidas de se ocupar de algo mais válido e corroboradas pela "inutilidade" de monges, será agora o que povoará o imaginário cristão ocidental. Oprimido pela Igreja, sucumbindo ao poder da aristocracia rural, tornado servo, o camponês perde a esperança.

Esse é um período de germinação de uma nova estrutura social e cultural. As famílias, refugiadas nos domínios feudais em busca de proteção, acumulavam-se precariamente. Nessa forma de organização, a mulher era muito pouco respeitada. Pouco a pouco, na medida em que as invasões bárbaras vão se distanciando na memória coletiva, a população se dispersa.

Nessa nova realidade, o núcleo familiar, composto pelo marido e sua esposa, deixa à mulher o papel de cuidar do lar enquanto o homem passa o dia fora. A mulher é então vítima de uma grande solidão. O mundo que a cerca e com o qual ela se comunica é o mundo da natureza, que, pela tradição pagã, é também o mundo do fantástico. Distante da realidade feudal-cristã, entregue diariamente a si mesma e a suas fantasias, a mulher tende a se aproximar do politeísmo, creditando aos antigos deuses - agora simples "espíritos" - seus próprios pensamentos e vontades. O homem, apesar de mais distante, entrega-se posteriormente e por influência de sua mulher às mesmas crenças proscritas pelo clero (MICHELET, 1862, p.59).

Era uma época de incertezas. Preso à terra por laços servis, o homem rural era explorado de forma intensa e cruel por seu senhor. A Igreja, antes de tudo grande proprietária de terras, colaborava 
para agravar ainda mais o quadro de opressão contra o servo. Vítima de ultrajes sem fim, fragilizada e massacrada pelo peso abusivo do clero e da nobreza, o homem medieval "sentia a ausência de Deus" $^{\prime \prime 6}$ (MICHELET, 1862, p.65).

A virada do milênio é acompanhada por mudanças nos "critérios de verdade" aceitos pela Igreja para atribuição de santidade. Ao povo é subtraído o direito de estabelecer suas lendas e criar seus santos. No mesmo período, o latim é adotado como língua oficial para as missas. De forma abrupta, o homem comum é afastado da Igreja. Ao mesmo tempo, a exploração do trabalho servil torna-se tão intensa que o século XII será marcado por grandes revoltas campesinas.

Ainda que seja o diabolismo a "heresia máxima" que mereça como punição a fogueira, é nessa direção que caminhará o camponês. Lentamente, aqueles "espíritos" da natureza vão, no imaginário medieval, se convertendo em Satã. Essa conversão, nos faz crer Michelet, se dá na medida em que o homem comum se afasta da Igreja e percebe no Deus cristão um deus de dor e sofrimento. Seu antípoda é, então, um "deus" de prazer e alegria, um desejado lenitivo que torne a aridez da vida no campo menos árdua.

A mulher - e em especial a feiticeira - será a responsável por capitanear essa nem sempre silenciosa resistência ao dogmatismo cristão. E o fundamento básico de tal resistência é a cura do corpo, negada pelos padres. Mas o profundo misticismo que marcava a cultura medieval atribuiu à feiticeira um papel adicional ao de curandeira: pessoas de todas as esferas sociais a ela acorriam em busca de algo mais que o consolo espiritual oferecido pelo padre; queriam soluções para os problemas que os afligiam, sejam eles de ordem material ou, como acontecia com freqüência, sentimental.

Respeitada e temida, amada e odiada, a feiticeira vulgariza-se; e com ela, satã. Elevada a uma condição social relativamente privilegiada, passou a ser consultada e protegida por nobres. Seu carrasco será a Inquisição. Se em um primeiro momento "a inquisição foi escarnecida, maldita, sobretudo na França"67 (MICHELET, 1862, p. 180-181), o recrudescimento das revoltas camponesas a transformava em uma útil ferramenta para "dobrar os espíritos rebeldes". É chegado o momento das feiticeiras, pelas mãos da Igreja, serem queimadas nas "santas" fogueiras, "hoje como feiticeiros aqueles que, talvez amanhã, se insurgiriam"68 (MICHELET, 1862, p. 181). Ao estabelecer de forma direta e explícita o vínculo entre a feitiçaria e a rebeldia política, Michelet coloca sua personagem em uma esfera diferente daquela outra, mais religiosa, que a feiticeira tradicionalmente ocuparia.

\section{O Herói Romântico}

Miguel Abensour, em seu trabalho o heroísmo e o enigma do revolucionário, parte de Tocqueville para desenvolver a seguinte proposta: o revolucionário moderno, esse novo protagonista

66

67

68
No original: "L’homme sentait l'absence de Dieu”.

No original: "L'Inquisition fut conspuée, maudite, surtout en France".

No original: “(...) briser les esprits rebelles, (...) comme sorciers aujourd’hui ceux qui, peut-être demain, auraient été insurges”. 
político surgido na e da Revolução Francesa, pode ser conhecido e reconhecido sob o rótulo de "herói" (ABENSOUR, 1992, p.207)? Interessa-nos aqui, no desenvolvimento de seus argumentos, conhecer mélhor quem é tal herói, especialmente nos pontos em que Abensour nos conduz à imagem de herói no pensamento político-historiográfico de Michelet e, mais especificamente, verificar em que medida a Feiticeira de Michelet pode ser compreendida como um construto desse ideal romântico de heroísmo.

De saída, estabelecemos que, se o ponto de partida de Abensour é 1789, é porque lhe interessa o revolucionário político. Aqui caberá analisar um tipo mais geral de revolucionário, o herói, ao qual pertenceria também o homem político da Revolução. Esse herói revolucionário, encontrado com freqüência em toda a obra de Michelet, seria, segundo uma perspectiva romântica, inerente à própria dinâmica da sociedade humana.

Recorrendo à etimologia, Abensour define "herói" como "todo combatente, todo homem nobre pelo nascimento, pela coragem ou pelo talento" (ABENSOUR, 1992, p.214). Concordando com Hanna Arendt em sua "definição sóbria", na qual o herói "não tem necessidade de qualidades heróicas" (ARENDT, 1988, p.117), nos aproximamos da concepção micheletiana de herói.

O heróié, ao mesmo tempo, um e muitos. Éna pluralidade-entendida como uma impessoalidade ou, ainda, um caráter público - que o herói se realiza. Ele é resultado de um "clima" da época, de um espírito que "emana fenomenologicamente das coisas, do mundo" (ABENSOUR, 1992, p.216).

Ao se tocar por essa "energia passional", o ator social migra de seu egoísmo natural para o interesse comum e, portanto, impessoal. Ele se prontifica a exercer o papel do mártir que se sacrificaria pela liberdade, seja o que significar, num contexto dado, tal liberdade.

Essa energia, esse espírito, adquire mesmo uma aura de força sobrenatural. É o que parece propor Quinet, quando ele celebra o heroísmo do periodo revolucionário. Para Lefort, tal heroísmo seria a "marca de uma nova religião" (LEFORT, 1991, p.245); Tocqueville, em quem Lefort se apóia para essa proposta, afirma que "essas paixões haviam-se tornado (...) como uma espécie de religião que (...) [impelia] para o heroísmo" (TOCQUEVILLE Apud LEFORT, 1999, p.251).

Tudo isso está em perfeita consonância com a idéia de herói para Michelet. Abensour afirma que

para Michelet, não é a qualidade subjetiva de tal ou qual, mas é em primeiro lugar um clima, o tom da época que afeta todos os atores e, prioritariamente, o ator principal, o povo, que passa do nada ao ser na própria experiência deste afeto" (ABENSOUR, 1992, p.217).

O momento emblemático desse caráter religíoso, místico, do heroísmo do povo é, ainda para Michelet, a Festa da Federação celebrada em 14 de Julho de 1790, com o objetivo de comemorar a comunhão proporcionada pelo início da Revolução. Emblematicamente, este episódio, com o qual Michelet encerra o Livro III de sua História da Revolução Francesa, é contado em capítulos intitulados "Da Nova Religião". 
Aliás, percebemos na história de Michelet, quase como uma constante, o político andando de mãos dadas com o religioso. É sobre as revoluções política e religiosa que ele se debruçará, e sobre tais processos paira sempre o espírito de seu herói maior, o povo. Aqui o historiador francês busca em Vico sua fórmula: o "heroísmo do espírito" é aquele que só se vincula ao indivíduo que não se exclui do povo. O espírito heróico, retomando o tema do sobrenatural, inspira no homem a superação de sua condição humana, divinizando-o. E o homem, ao divinizar-se, perde sua subjetividade. Torna-se povo. Portanto, é o povo quem constrói a si mesmo e aquele que se mantém à distância desse povo é infiel ao princípio do heroísmo.

Se, de maneira mais ampla, o grande herói de Michelet é o povo, a ênfase deste historiador recairá especialmente sobre o povo francês do século XVIII. É assim que, ao falar do "método e do espírito" da obra História da Revolução Francesa, ele o chama de "verdadeiro rei" e afirma: "o povo é tudo" (MICHELET, 1979, p. 34). Em decorrência, percebemos também que um indivíduo só pode imbuir-se do espírito heróico na medida em que ele se anula enquanto subjetividade e transmuta-se em defensor dos interesses coletivos; na medida em que se torna nada mais que "povo".

Lucien Febvre, em seu livro Michelet, nos fornece essas palavras que dão o tom do nosso argumento:

\begin{abstract}
"Um homem? Porque não vários? Porque não mil? Porque não todos? Veja a Revolução, ela prescinde de modelos, de homens mesmo, e de heróis. Apareceram os heróis, ela se extinguiu. O Instinto? Sim, mas o instinto de todos." ${ }^{\prime \prime}$
\end{abstract}

Por vezes esse povo, esse monstro de várias cabeças e de uma só vontade, parece escapar a Michelet. Ao olhar para seu próprio tempo, ele mostra-se desesperançoso: "o povo, em sua idéia mais elevada, é difícil de encontrar no povo" (MICHELET, 1979, p.31). Onde, portanto, se não no povo, podemos encontrar esse povo-herói? No homem de gênio, naquele que consegue descobrir o povo, a despeito do próprio povo e, contra sua aparente multiplicidade de interesses, converge sua ação em direção a uma insuspeita homogeneidade de vontade, de aspirações. Tal genialidade, que em uma perspectiva não-romântica conduziria talvez a uma concepção individualista de herói, aparece aqui como uma manifestação individual dos interesses mais gerais de um dado grupo social, e só nessa medida o "homem de gênio" pode aspirar à condição de herói.

Eis, porém, a interrogação que nos colocamos: o que faz do povo esse herói inconteste? O que representa ele que lhe dá tal status de símbolo máximo do herói micheletiano, a ponto de Michelet afirmar: "não compreenderei os séculos monárquicos se, de início, antes de mais nada, não fincar em mim a alma e a fé do povo" (MICHELET, 1979, p.33)? Diversas, inesgotáveis mesmo, seriam suas declarações nesse sentido, o do povo como o ator principal da história. Diria ele ainda, em uma bela metáfora, que após muito escavar, descobriria que o melhor estava no fundo. O calor que possibilitaria 
a incubação desse espírito de heroísmo. Por outro lado, quanto maior a altura, quanto mais subisse imaginemos aqui uma montanha representando uma pirâmide social - mais rarefeita era a "vegetação moral" e mais fria aquela parcela do povo (MICHELET, 1979, p.34).

Avancemos, pois, em nossa já posta interrogação, em direção à resposta que nos será fornecida por Roland Barthes. Mas antes, escutemos ainda mais uma vez a voz de Michelet:

"O último herói que apareceu não foi Napoleão, como se diz, mas a Revolução, e sua grandiosidade consistiu justamente no fato de que ela não dependeu de um grande homem. Ela apresenta esse grande e novo espetáculo de uma idéia que prescinde de grandes homens, de heróis, de falsos deuses, de ídolos. Ela foi, ainda mais que Kant, a crítica da razão pura"70.

Aquilo afirmado por Febvre, que para Michelet a Revolução prescinde de modelos, é aqui confirmado. Ao mesmo tempo, a Revolução, "crítica da razão pura", confirma e retoma o tema do heroísmo místico, a Revolução como religião, apontado por Lefort.

A hermética epígrafe de Michelet, por Barthes, nos dá a chave para desvendarmos essa questão e, por conseguinte, o herói micheletiano:

"Sou um homem completo

Possuo os dois sexos do espírito"71

Na interpretação de Barthes, o que Michelet trata por "sexo do espírito" é uma dicotomia encontrada já em Vico: a verdade cartesiana (verum) em oposição à verdade sentimental (certum). Assim, o século XVIII, tão louvado por Michelet, começa incompleto, cerebral. Seus filósofos iluministas são cartesianos, do que Barthes chama de sexo espiritual masculino. A Revolução, porém, redime as primeiras décadas oitocentistas ao trazer à tona a paixão do povo, e com isso o equilíbrio dos sexos espirituais masculino e feminino. Eis o herói micheletiano para Barthes: um ser andrógino, de gênio intelectual amparado por uma intuição "sobrenatural". Barthes lista exemplos: Joana d’Arc, Lutero, Hoche (BARTHES, 1991, p.150). E, retomando a epígrafe acima citada, Michelet é, ele próprio, um herói micheletiano.

Eis então a primeira característica do povo-herói em Michelet: o que chamaríamos de "androginia espiritual", com predominância fêmea, segundo Barthes. O povo representaria o "ultrasexo", a combinação ideal da razão e da emoção, do verum e do certum. Barthes é lapidar: "tudo o que participa da idéia pura é conduzida ao estéril" (BARTHES, 1991, p.150). Assim, quando a sabedoria isola-se do povo, torna-se puramente cerebral e, portanto, uma "caricatura da sabedoria". Eis porque a Revolução se perdeu: perdeu-se a tradição do povo. Sobrou à França a "salvação" - Robespierre, o

70 Le dernier héros qui air paru, ce n'est pas Napoleón, comme il disait, c'est la Revolution, et sa grandeur consista justement en ceci qu'il n'y eut point de grand home. Elle présente ce grand et noveau spectacle d'une idée qui s'est passée de grands homes, de héros, de faux dieux, d'idoles. Elle a été, bien plus que Kant, le critique de la raison pure (MICHELET Apud FEBVRE, 1946, p.66)

71 "Je suis um homme complet, ayant les deux sexes de l'esprit" (BARTHES, 1991) 
Terror, representam o abandono da paixão, o masculino sobrepondo-se, o puramente racional, frio, enfim, o estéril.

Mas, afinal, onde podemos encontrar esse povo? Ao usar a expressão cunhada por Lutero - herr Omnes - Michelet aponta no sentido de um escopo amplo, universal. Se o povo é esse "senhor TodoMundo", ninguém é excluído e o conceito de classe - especialmente classe social - não encontraria aqui um lugar.

Mas ao mesmo tempo, e aqui observamos uma segunda característica do herói micheletiano, o povo é fraco, é o que sofre. Por decorrência, sofredores serão seus heróis: Godofredo de Bouillon, Thomas Becket, São Luís, o camponês Jacques, todos vencidos. A derrota é o embrião de uma vitória futura, os oprimidos de hoje serão os heróis de amanhã. Barthes chamará isto de "dialética cristã da inversão" (BARTHES, 1991, p.155); em última instância, os últimos serão os primeiros.

Tomamos como terceira característica desse herói, já amplamente discutida, a sua capacidade - necessidade mesmo - de se anular como indivíduo em prol do interesse público.

Quarta e quinta características: a simplicidade e a justiça. Simples, aqui, aparece no sentido contrário ao da erudição; o herói micheletiano é, em certa medida, infantil, ingênuo, movido pela intuição, mais próximo do sexo espiritual feminino. A justiça é particularmente importante para entendermos esse mártir, sofredor, que se doa em benefício do povo, que muitas vezes vê onde estará tal benefício mesmo quando o povo permanece cego, e sacrifica-se por ele. Se com freqüência o que se abate sobre o povo é a injustiça do mundo, ele, o herói, é o que impõe a justiça na história. Em sua tradição, em seu pensamento, na Lenda Nacional, encontra-se a própria credibilidade da História. "O que o povo acredita é verdadeiro, o que ele faz é bom" (BARTHES, 1991, p.153). Michelet, em sua História da Revolução Francesa confirma: "Quando ele [o povo] julga, tudo está acabado. Cabe a vós, historiadores (...) encontrar, se puderdes, o porquê. Procurai; ele é sempre justo" (MICHELET, 1979, p.35).

Eis então nosso herói: sofredor, simples e justo; ao mesmo tempo racional e sobremaneira emotivo - andrógino, na perspectiva de Barthes. Várias personagens nas obras de Michelet assumirão tais predicados - Joana d'Arc, Rabelais, Leibniz, Kosciusko - além de outros tantos já citados. Mas só com uma condição muito específica eles atenderão pela alcunha de heróis: enquanto estiverem associados ao povo. Enquanto eles forem capazes de perceber e representar o espírito da época, o stimmung. Enquanto forem, enfim, o que é para Michelet o herói sui generis, o povo.

\section{A Feiticeira: um herói micheletiano}

Desta forma, não nos basta - apesar de ser essencial - encontrar na feiticeira de Michelet o sexo espiritual feminino, ou seja, a emotividade sobrepujando a racionalidade; a condição de submeter-se a um mundo de injustiça e em troca oferecer ao mesmo mundo o sacrifício em nome da justiça; a simplicidade que se opõe à falsa sabedoria dos eruditos. Devemos, mais que tudo, verificar 
em que medida é a feiticeira um representante dos anseios populares; até que ponto ela é resultado do "espírito da época", síntese de uma vontade superior, a vontade do povo.

Nos dois primeiros capítulos do livro A Feiticeira, Michelet procura responder à seguinte questão: "porque a humanidade perdeu a esperança"? Ao partir de uma inquietação tão ampla para traçar a trajetória de sua personagem, Michelet nos mostra uma feiticeira que é, como o são normalmente os heróis românticos, fruto de seu tempo, resultado das aspirações comuns.

No processo histórico de surgimento da feiticeira, Michelet identifica o ritual do sabá como momento central. Manifestação e representação do martírio popular, ele é resultado de um "abismo de dor" ao qual é lançado o povo. É desse ritual que emerge a feiticeira, na condição de porta-voz do calvário do povo. A feiticeira, portanto, surge como síntese da dor na qual foi mergulhado o camponês, o europeu comum do medievo (MICHELET, 1862, p.142).

Lembremos que, para Michelet, o herói é o justo, injustiçado pelo mundo; pois eis o contexto em que nasce a nossa feiticeira: bons camponeses vivendo um inferno em vida (MICHELET, 1862, p.43). A Igreja oprime, impõe sua "metafísica bizantina" e, em oposição, o povo procura no paganismo um refúgio, uma arma de resistência. A feiticeira, como peça-chave do paganismo, é portanto a detentora das armas que levariam o campesinato à liberdade contra o Clero. "De quando data a Feiticeira?", pergunta o autor. E ele mesmo responde em seguida: "Do desespero profundo que provocou o mundo da Igreja"72 (MICHELET, 1862, p.XIV). Elas, feiticeira e desesperança, são frutos de uma realidade imposta pelo Clero.

Vale observar o óbvio: a feiticeira é sempre uma mulher; segundo Michelet, discriminada pela Igreja, surrada em casa e imolada no sabá. A mulher ocupa o lugar central no paganismo grego, desde a sibila, que prevê a sorte, até a feiticeira, que a faz. E de sua feminilidade derivam suas características fundamentais: o que Michelet chama de "iluminismo da loucura lúcida" (MICHELET, 1862, p.XVII) - que nos parece uma contraposição à razão pura do sexo espiritual masculino - e a criatividade própria de sua condição de mulher, uma vez que, à fecundidade do corpo, corresponde também uma fecundidade do espírito. Eis porque Michelet afirma que com o "feiticeiro macho" nada teria começado. De sua feminilidade e de sua predisposição ao martírio estabelece-se a simbologia máxima de sua entrega ao povo: o ritual do sabá, o verdadeiro sacrifício onde a mulher se oferece como hóstia viva (MICHELET, 1862, p.XVIII).

Segundo Paracelso, o que ele aprendeu sobre medicina veio dos conhecimentos acumulados pelas feiticeiras. Em troca de tal legado, elas foram perseguidas, violentadas e queimadas ${ }^{73}$ (MICHELET, 1862, p. XI). Nesse ponto, cabem duas observações: acreditamos que a utilização da figura de Paracelso não é gratuita. A idéia de herói para Michelet parece bem sólida em sua argumentação e aqui teríamos a princípio um problema: a feiticeira, se comparada ao campesinato, é detentora de conhecimento, é sábia. Ora, se o herói micheletiano afirma-se na simplicidade, na proximidade com 72

73 "Isso merecia uma recompensa. Elas a receberam. Foram pagas em torturas". No original: "Cela valait une récompense. Elles l'eurent. On les paya en tortures". 
a tradição popular, a inclusão de Paracelso teria, em nosso ponto de argumentação, uma função que mais tarde, nos autos da Inquisição, terão os doutores da Igreja: servir de contraponto para aproximar a feiticeira do povo. A feiticeira representa então a sabedoria popular, contra os ditames da ciência, da medicina e da religião oficial.

Por outro lado, a sabedoria da feiticeira é fundamentada no saber fazer, enquanto a de Paracelso é supostamente tirada dos livros, racionalizada, erudita e, portanto, na análise de Barthes, representante do sexo espiritual masculino. Destarte, a aproximação da feiticeira com o surgimento da ciência moderna dá a ela a androginia que Barthes afirma estar presente no herói micheletiano.

A segunda observação diz respeito ao tratamento irônico dado à questão da recompensa. $\mathrm{Na}$ própria forma da escrita, de frases curtas, cortantes, percebe-se o objetivo de Michelet. Ele toma partido, se posta ao lado da feiticeira e aponta um dedo contra a Inquisição: o herói sacrifica-se pelo povo e sofre em um mundo de injustiça. Quando podem, as acusadas evitam a tortura e se matam.

Barthes diz que uma das armas do herói micheletiano é o riso (BARTHES, 1991, p.53). Pois na Introdução da Feiticeira, Michelet deixa claro o papel da feiticeira, quando seu grande inimigo, a Igreja declara: "Desgraçadas aquelas que riem!"7" (MICHELET, 1862, p.XIX). O riso, dirá Michelet, é uma importante função da própria natureza humana. O que faz a feiticeira no crepúsculo de sua história? Ao partir ela ri, solta a mais terrivel gargalhada e desaparece como uma flecha (MICHELET, 1862, p.168).

Se o herói micheletiano, como já observamos, é por definição o povo, qual a relação da feiticeira com o povo? É a ela que todos procuram em suas necessidades. Ela representa o confessor, o médico, conselheiro. É ela esse espantoso poder que une todos os outros (MICHELET, 1862, p.126). Em alguns momentos o povo parece a tal ponto desorientado que se imobiliza. O herói será aquele que consegue descobrir o espírito e a vontade desse povo e, agindo em nome deste, sacrifica-se em busca da justiça.

Para Michelet, é na opressão dos senhores que surge a Feiticeira, e é na sua ausência que ela cresce. Ela não só assume para si a grandiosa tarefa de canalizar a desesperança do povo, mas o faz com freqüência sem que o próprio povo se dê conta disso. E poucas vozes se levantam quando ela queima nas fogueiras. 


\section{BIBLIOGRAFIA}

ABENSOUR, Miguel. O heroísmo e o enigma revolucionário. In.: NOVAES, Adauto (org.) Tempo e História. São Paulo: Cia das Letras, 1992.

ARENDT, Hanna. Da Revolução. São Paulo: Ática / UNB, 1988.

BARTHES, Roland. Michelet. São Paulo: Cia das Letras, 1991.

FEBVRE, Lucien. Michelet. Geneve-Paris: Trois Collines, 1946.

LEFORT, Claude. Pensando o político. Rio de Janeiro: Paz e Terra, 1991.

Desafios da escrita política. São Paulo: Discurso Editorial, 1999.

MICHELET, Jules. História da Revolução Francesa. Lisboa: Publicações Europa-América, 1979.

La Sorcière. Paris: E. Dentu Libraire-Editeur, 1862. Disponível digitalmente.

WILSON. Rumo à estação Finlândia. São Paulo: Cia das Letras, 1986. 